\title{
Cross-Cultural Peer Mentoring: One Approach to Enhancing White Faculty Adjustment at Black Colleges
}

\author{
Dave A. Louis \\ Texas Tech University \\ U.S.A.
}

\begin{abstract}
White faculty members at Black colleges in the United States face numerous social obstacles. Exploring the experiences of White faculty members at four historically Black colleges and universities (HBCUs) and their adjustment to a minority status assists the comprehension of issues surrounding this subgroup. Utilizing a phenomenological approach, narratives from 27 White faculty members were analyzed to garner an understanding of their experiences at these colleges. The discussion addresses strategies for developing faculty peer-mentoring that would assist adjustment for the White faculty. Greater engagement is recommended for Black and White faculty to assist White faculty with adjusting as minorities at these culturally important and historic institutions.
\end{abstract}

KEYWORDS: higher education, White faculty development, cross-cultural peer mentoring, Black colleges, diversity

\author{
History of HBCUs and White Faculty Involvement \\ Conceptual Framework \\ Method \\ Results \\ Discussion \\ Recommendations \\ Conclusion \\ References \\ Appendix A \\ Author Contact
}

\begin{abstract}
As the U.S. population becomes increasingly diverse and minority groups may eventually constitute a majority population (Frey, 2012), it becomes increasingly relevant to comprehend the experiences of Whites who find themselves in minority positions. Unlike Blacks and other minorities, whose experiences have been researched more extensively, White individuals in minority situations have not been comprehensively explored. Many universities boast of environments where diversity is valued and practiced more than it is in many other arenas in society. It may be correct that the U.S. university campus today is at its most diverse state (Quaye \& Harper, 2014). However, there is an institution within the academy that has been overlooked, one in which ethnic
\end{abstract}


diversity has been commonplace since its inception: the historically Black college and university (HBCUs) (Kynard \& Eddy, 2009). Today these institutions continue to be the epitome of diversity, particularly for faculty. Foster (2001) states, "With respect to faculty ranks, HBCUs are more racially diverse than predominantly White institutions of higher education in the United States" (p. 613). These Black colleges may be crucibles where research on the experiences of White faculty members as minorities can take place. Such research may assist university administrators, departmental chairs, and provosts in the development of approaches for addressing current and future experiences of White faculty members. Information on the experiences of White faculty members can open the discourse on the design of cross-cultural programs and structure of faculty peer-mentoring programs. Specifically these programs can address minority status adjustment of White faculty members.

\section{History of HBCUs and White Faculty Involvement}

HBCUs were the first schools dedicated to the uplift and education of Blacks in the United States. The vast majority of these institutions were developed prior to the Emancipation Proclamation Act of 1893. Today over 100 HBCUs exist in the United States (Roebuck \& Murty, 1993; U.S. Department of Education, 2014), about three percent of all colleges and universities. These institutions have been instrumental in fortifying the educational opportunities and fostering the leadership core of the Black community in the United States (Betsey, 2008; Willie, Reddick, \& Brown, 2006). The vast majority of African Americans who earn a terminal degree acquire their first degree from an $\mathrm{HBCU}$ (Betsey, 2008). Hubbard (2006) points out that it is the HBCU that continues to produce the majority of African Americans within the faculty ranks, and without them the landscape of the university would have been drastically different. Also over $50 \%$ of African Americans who earn a bachelor's degree in sciences are products of HBCUs (Czujko, Ivie \& Stith, 2008). HBCUs provide African Americans with access to the graduate school pipeline. Thus the HBCU is a necessary component of today's U.S. higher education landscape.

Although generally unheralded, Whites have been present in Black college life since the beginning. Benefactors, trustees, presidents, administrators, and faculty members are some of the roles of Whites held during the birth of Black colleges (Foner, 2002; Foster, Guyden \& Miller, 1999; Gasman, 2009). Whites, especially in the early years, were seated in positions of leadership and influence. Today, this is not the case: positions of power, influence, and privilege at most HBCUs are held by Blacks. This paradigm is antithetical to the larger society where the locus of power rests within the White community. Thus, many current White faculty members entering the $\mathrm{HBCU}$ environment struggle with their newfound status as a minority.

White faculty members have historically faced numerous challenges garnering the trust and confidence of Black faculty peers, administrators, and 
students. In a seminal study, Warnat (1976) explored the negative typologies of White faculty that emerged from the sentiments of Blacks on HBCU campuses. These typologies portrayed White faculty members as disingenuous, academically inferior, and guilt-riddled entities. To this day, many White faculty members endure these negative perceptions as they attempt to accomplish their duties (Louis, 2008). Adjustment to being a minority is fundamental when attempting to fully understand the experiences of White faculty at Black colleges. Smith and Borgstedt's (1985) pivotal piece was one of the first to examine, via self-reporting, the adjustment of White faculty to the HBCU environment.

In this environment, the social climate is one of Black-in-charge, White as subordinate. Since racial inequity issues are very salient topics at HBCUs, these occurrences become the first time many White faculty engage in a discourse on racial inequality, and concurrently they engage in the discourse in the role as a minority in the $\mathrm{HBCU}$ environment. Many of the White faculty members have dealt with racial discrimination minimally or only on an intellectual level but not from a collective community experience. Being employed at an HBCU forces many of the White faculty members to confront the issue of race as a social ill. More so, many White faculty members had to engage in self-reflection about their own reactions, personal prejudices, and beliefs which may be barriers to effective interracial relationships.

Louis (2008) built upon Smith and Borgstedt's (1985) framework and found that 20 years after the aforementioned study, White faculty remain maladjusted to the HBCU environment regardless of rank, gender, or length of time at institution. Both studies defined adjustment as White faculty members' level of satisfaction and comfort with their current employment at an HBCU and their ability to cope and adapt to a minority status. The studies concluded that White faculty members were ill-prepared because they had not previously experienced being in a sub-dominant position. Prior to Louis, Cooper, Massey, and Graham (2006) examined the sentiments and experiences of White faculty members at HBCUs, and one participant openly expressed, "I was not prepared for an identity crisis when I accepted a faculty position at a historically Black university..." (p. 117). It is within this personal cultural crisis that examination, comprehension, and action must take place.

Coping mechanisms for minorities are essential to their survival in the larger society (Butera \& Levine, 2009). Whites, however, have not normally had the experience of being in a minority situation. Hence, coping mechanisms are not cultivated throughout their lifetimes, and this exacerbates the difficulty for many White faculty members to adjust to the Black college environment. Louis and Michel (2013) utilize Fanon's (1969) idea of ambivalence to describe the psychological self-doubt that individuals experience when interacting with someone of a differing ethnic background. The ambivalence occurs concurrently while the individuals also strive to gain the other's acceptance. Fanon describes this phenomenon of self-doubt and acceptance-striving within the Caribbean Black community as they embarked on interfacing as co-citizens with Whites soon after Emancipation. Similarly, the self-doubt and acceptance-striving 
phenomenon can frequently occur when White faculty members attempt to interface and gain acceptance at the Black college. White faculty members strive to become part of their university's community and interact positively with Black peers, administration, and students, while endeavoring for acceptance and respect. The process of integration, while concurrently desiring acceptance, is a common practice to many minority groups in the United States. These groups consciously attempt to preserve their cultural heritage while continually interfacing with, and sometimes succumbing to, a dominant society and culture. Generally, Whites in the United States do not possess the cultural history of subjugation and typically have no social practice of succumbing to other dominant racial groups.

Capturing the voices of White faculty members as they struggle with their minority status at a Black college is an important component of understanding their experiences. In Foster, Guyden, and Miller's study (1999), White faculty were given the opportunity to express their experiences, realization of ethnic imbalance, oppression via minority status, personal reflection, and ambivalence. One faculty member stated,

I was immersed for a brief moment in a scene where I was the different one. Shortly, thereafter, I read something about Black people often facing an all-White world and that more Whites should experience the reverse phenomenon of existing in an all-Black world... Why am I at an HBCU? I certainly don't think of myself as a missionary? Do others think of me that way? (p. 38)

Finding ways to assist White faculty adjust is of paramount importance if Black colleges intend to recruit, retain, and optimize their White faculty. An intimate, personal, psychological, and impactful approach is necessary.

\section{Conceptual Framework}

Capturing the voices of the White faculty members at Black colleges is central to this study, and the use of counter-storytelling as a form of critical race methodology (Solórzano \& Yosso, 2002) allows for the experiences of the participants as a minority group to be expressed directly. In a relevant yet unorthodox manner I decided to adopt Critical Race Theory as the theoretical framework for the study, since the population being examined is (a) a cultural minority in the environment in the context of Black college campuses; (b) a numerical minority in this context; and (c) in a subdominant position with respect to power and influence in this context. The utilization of the voices of White faculty employed at Historically Black Colleges and Universities (HBCUs) in the United States legitimately highlights the currently shared lived experiences of this population. Stories and narratives many times can offer deep insight into the experiences of individuals and groups and can speak to other interconnected and invested groups (Reddick \& Saenz, 2012). Thus, an approach which would utilize 
the voices of White faculty at HBCUs in today's academy became central in the method I decided to use to best highlight their lived experiences.

Critical Race Theory (CRT) recognizes the plethora of prejudices that permeate research, policy, and law, even with the intentional efforts towards race-neutrality (Smith, Altbach, \& Lomotey, 2002). In many ways CRT takes the shape of a movement that is driven by scholars and social activists whose goal is to shed light on the imbalances that exist as a result of race, racism, and power. CRT also takes into consideration the context of the given situation including "history, context, group- and self- interest, and even feelings and the unconscious" (Delgado \& Stefancic, 2006, p. 1).

For this study I considered context, history, and power as major elements in choosing CRT as a framework. At an $\mathrm{HBCU}$, the power structure is the inverse of that of the greater society. Power and privilege are held by Black individuals including administrators and faculty members, whereas in the greater society the dominant culture is White. Thus in many instances White faculty members in the $\mathrm{HBCU}$ environment are in the sub-dominant culture and do not possess privilege and power in this environment. This inversion makes White individuals who are not commonly the voices for CRT research applicable for this specific study. In essence this study views the societal dominant racial culture as the locally subdominant racial culture, and thus CRT fits as an appropriate theoretical framework.

CRT's framework is comprised of five tenets, of which counter-storytelling is one (Hiraldo, 2010). According to Ladson-Billings (2005) counter-stories can assist in the analysis of the climate of a college campus and furthermore provide the foundation for future research. She continues to state that the information gained from this approach can provide institutions with ways to become more truly inclusive of diverse populations on their campuses. Thus the counterstorytelling element of CRT is a framework that gives credence to the subordinate experiences of White faculty members at HBCUs and could shed light on ways in which these institutions can assist these individuals become adjusted to the college climate.

Solórzano and Yosso (2002), critical race methodologists, state that counter-storytelling is "a method of telling the stories of those people whose experiences are not often told" (p. 26) and highlights the human aspect to the experiences of marginalized populations. Counter-storytelling as a framework also legitimizes the racial experiences of subordinate and marginalized populations (DeCuir \& Dixson, 2004).

I was extremely cautious in using CRT to frame this study since in essence the participants are still members of the majority and dominant population in the larger societal context. According to Delgado and Stefanic (1993), individuals in this group when discussing their experiences exude and express their "presuppositions, perceived wisdoms, and shared cultural understandings [that] persons in the dominant race bring to the discussion of 
race" (p. 462). In essence their White privilege, enjoyed in the larger society, bleeds into their narrative and perspectives.

The knowledge gained from the narratives of the White faculty members in this study is invaluable to discourse on the experiences of subdominant populations. The voices represent an acknowledgement of the significance of their lived and shared experiences. Maher and Tetreault (1993) posit that "knowledge is valid when it includes acknowledgement of the knowers' specific position in any context" (p. 118). For this study, knowledge was derived directly from the experiences of the participants as White faculty on Black college campuses. Each participant understood that their experiences were distinctive to them as individuals. They were aware that their experiences and opinions may be shared by other White faculty in similar contexts. Thus, collecting, analyzing, and gaining a greater level of understanding of the experiences of White faculty members at HBCUs through research are necessary.

\section{Method}

All data collection and analysis for this study are based on qualitative research methods (Creswell, 2008; Lincoln \& Guba, 1985; Patton, 2001). The approach was rooted in a philosophical tradition, interpretive phenomenology, which explores the perspectives of individuals and how they understand their personal and social worlds through an examination of their lived experiences (Smith \& Osborn, 2008). Individual interviews of 27 White faculty members from four Black colleges were conducted. The HBCUs were located in three different states. The purpose of the interview data was to gain an emic perspective of the group of faculty and to garner a greater understanding of their shared experiences at Black colleges. Besides some initial demographic data, 10 openended questions were developed that addressed (a) the participants' perception of their interactions with Black administrators, faculty members, and students at the HBCU; (b) the participants' positive experiences and interactions at the $\mathrm{HBCU}$; (c) the participants' negative experiences and interactions at the HBCU; and (d) participants' suggestions for ways to enhance the experiences of White faculty members at the HBCU (Appendix A). The interviews were scheduled for 45-60 minutes, although some interviews continued beyond the allotted time. Follow-up questions were asked in individual cases to bring clarity to any answer that may have been deemed unclear or not descriptive enough by the interviewer.

I initially contacted White faculty members from eight institutions from four states; however, only faculty from four institutions from three states responded. Different states were selected to ensure that one regional or state-focused set of factors would not influence the responses of the participants. 


\section{Participants}

Twenty-seven faculty members were interviewed about their experiences at Black colleges. To ensure that the experiences of the White faculty members were not simply a reflection of a particular institution, region, or state, faculty from four universities located in three different states were interviewed. This also assisted in the triangulation process, since data were collected from different sources at different institutions. Of the 27 participants, 16 were male and 11 were female. With respect to rank, males ran the gamut from instructors to full professors; the majority held the rank of full professor. Female participants ranged in rank from assistant to full professor with the majority being assistant professors. The average number of years that the male faculty members taught at the HBCU was 12.06 years; the average for the female faculty members was 10.91 .

\section{Data Analysis}

A qualitative approach was used for this study. Data collection occurred during the academic year 2013-2014 through in-depth, semi-structured interviews with individual participants. Data were collected using interviews and narratives were transcribed. The narratives were analyzed using open coding of the narrative text to expose the meanings, ideas, and sentiments embedded. The study intended to explore the experiences and perceptions of the White faculty members from their own perspectives. The data collected were the narratives from the responses to the non-directive, broad questions posed. After collecting the responses, data were coded into a set of themes which were analyzed to determine their meaning. I highlighted pertinent statements, common quotes, and similar sentiments of the participants. Thus common features emerged to describe the White faculty members' experiences as employees at Black colleges. The participants' narratives led to a composite description and ultimately provided an understanding of their common shared experiences. I did not at the beginning of the study develop a preconceived framework or constituent topic to measure or evaluate. Instead, from the interviews, transcriptions, and interview notes, themes and patterns were identified. An open-coding approach was used to identify recurrent themes and patterns, which were then sorted into categories. The major themes were topics that were echoed by the majority of participants. Other lesser mentioned themes emerged also from the narratives.

\section{Participants' and Researcher's Positionality}

The narratives quoted below were from interviews of White faculty members employed at HBCUs for this project (Appendix A). The idea of developing narratives of White faculty members at HBCUs came as a result of discussions surrounding invisible minorities and White faculty members who 
shared their experiences in minority situations. Even though each faculty member may have a different background, may have different rank, and may be from a different $\mathrm{HBCU}$ in a different region of the country, there were numerous threads and recurring themes that connected their experiences. My assumption was that a common voice of White faculty at HBCUs and their experiences in a minority situation may emerge from the common threads recognized during their discussions. The nature of qualitative research sets the researcher as the data collection instrument. Bourke (2014) states:

$[T]$ he researcher's beliefs, political stance, cultural background (gender, race, class, socioeconomic status, educational background) are important variables that may affect the research process. Just as the participants' experiences are framed in social-cultural contexts, so too are those of the researcher. (p. 2).

Therefore, the biases and perspectives of the researcher shares in the study and are necessary to understand the context of the research.

The positionality of the researcher also influenced the study. I am a Black male who was an HBCU graduate and former HBCU administrator who worked closely with White faculty at HBCUs. Takacs (2003) states, "Only I have lived my life; only you have lived yours. This encourages me to listen to you and you to me, as we each have a unique perspective" (p. 29). Thus, the positionality of the researcher as a Black individual affiliated with HBCUs is important in the "listening" aspect of this research area. Having Black individuals listen to the perspectives of another minority group in which the majority is Black can result in the development of new perspective of minority status.

The positionality of the White faculty participants is necessary, as it reflects their personal bias, viewpoints and individual perspectives. It is within these personal perspectives that the study is valid and warranted. Positionality makes this approach epistemologically sound and authentic.

\section{Results}

Contribution to the discourse on diversity was the first theme that emerged from the narratives. White faculty members felt that they were important contributors to their respective institution's diversity. Participants spoke about their ability to contribute to discourses on campus and lend their perspectives to enrich conversations. Coupled with adding value to the campus discourse was the sentiment that participants believed they experienced personal growth and heightened awareness of social inequity by being at an HBCU. One female associate professor spoke about her ability to add to the diversity of opinions to the general discussion on campus both as a woman and as a White person. She stated:

I believe that I have added my voice to the mix at [my campus]! I'm not sure that it is solely my voice, but the few Whites who are professors here 
have brought a different way of thinking. I think we have given the provost and the entire campus some things to chew on and maybe even changed the perspectives of some individuals. I've notice changes in my colleagues... they listen to what I have to say and have had some actually thank me for bringing up something new. I am also very open about my feminist leanings and that too has influenced many here [at the campus] to keep women in mind when decisions are being made. So, yeah, I think my presence here at [my campus] has helped in opening up conversations and minds.

She continued by stating that she believed that her contribution may have opened the eyes of many, just as much as her eyes had been opened by others' experiences.

A second positive theme that emerged was the increased awareness of White faculty members' about racial discrimination and cultural relevance of a community. A male associate professor expressed how much he had learned about diversity,

Being at a Black college showed me how racist and discriminatory the world is. I didn't think I was part of the problem before joining the faculty. But being here I have learned that I have a responsibility not only to African Americans but to Whites to create a better world.

A female assistant professor expressed, "There is no better experience than being a minority to improve one's humanity. It allows me to see the interactions and power struggles that aren't visible when always a majority member." Thus the subdominant station at an HBCU allowed some of the participants to develop an awareness of the social imbalances that other minorities experience in the larger society.

Many faculty members spoke about the fact that they would not have had the same level of cultural awareness if they had accepted a post at a predominantly White institution (PWI). Participants also expressed a change in their perceptions of the greater society, the Black community, and their personal beliefs. A female full professor said, "Working at an HBCU has broadened my own experiences about African American culture.... I have developed friendships that I probably would not have had the opportunity to [develop if I were] working at a White institution. Working here has undoubtedly changed my life." Personal growth via the subdominant experience was indeed expressed by the majority of participants, especially the opportunity to develop friendships with individuals from a differing culture.

Two negative themes emerged from the interviews with the White faculty. The first negative theme that emerged from the narratives was unacceptance professionally. The participants perceived that Blacks did not want Whites to be part of the university or college. Imbedded in this theme was the belief that Whites were not readily promoted or accepted in positions of influence and power. More than half the time when participants mentioned their perception that Blacks did not want them as part of their colleges, they concurrently mentioned 
limited opportunities for promotion. One male full professor explained his scenario when he was a department chair:

When it came time for me to select an assistant chair, my choice, a White colleague, was vehemently vetoed by the Black faculty. They were not at all happy with the idea of two White faculty [members] leading the department.

Thus the perception that White faculty members were marginalized and not promoted fairly or via merit is significant to their overall experience at an HBCU. Similarly, in a very animated manner a female assistant professor expressed,

To some faculty my actions are outweighed by my skin color. They project political alliances and motivations onto me regardless of logic or experience. It is infuriating.... I regularly debate leaving but have remained due mostly to student relationships.

Her unacceptance by peers professionally based on her ethnicity was a major concern and was echoed by almost every participant in the study. Another female faculty member plainly articulated her frustration, "There are some faculty members, they may be small in number, who voice their opinion openly that White faculty don't belong." Frustration and anger with the marginalizing environment was usually paired with the sentiment of being unaccepted.

The second major negative theme emerged from the narratives as White faculty members responded to the question, "What is the most difficult aspect of being a White educator at a predominantly Black college?" Many White faculty members reported experiencing social isolation. The participants shared their experience of not being included in social groups inside and outside of the university setting. They discussed that they had no idea about the meaning or the cultural significance of events on campus. A female full professor voiced her incomprehension and feelings of being on the periphery of events that the institution sponsored, such as balls, banquets, and pageants. "I do not get it... there are these large formal functions...glitzy... and I don't understand their purpose except for self-aggrandizement.... Black rhetoric [statements] at these function to me are very divisive! Don't do Black rhetoric, be inclusive."

Other participants described their experiences of not being invited to participate in social events or gatherings frequented by Black faculty members. A male associate professor took on a more saddened disposition when he spoke of his perception of being marginalized:

l'd only by chance hear them [Black faculty] in the department talk about their weekend golf hangout together or a gathering at their homes. I don't think it is intentional but I do feel that they do not realize that I would like to be a part of their social circle.

Thus social isolation both at the institutional level and at the social level were concerns for White faculty at the four Black colleges.

Other less commonly voiced themes emerged from the narratives beyond the aforementioned themes of contributing to diversity, increased cultural 
awareness, unacceptance, social isolation, and professional marginalization. A few participants spoke about (a) the friendliness of the students at their colleges; (b) being inspired by the commitment of the faculty and staff about serving at a predominantly Black college; (c) the heavy teaching load at their respective HBCUs coupled with the lack of opportunities for research; and (d) the financial woes that their institutions experience on an ongoing basis. Each of these was mentioned by fewer than seven of the participants, and was not a major focus of their discussions. However, by the fact that it was mentioned by a few individuals, I determined that they were not major themes.

Participants, nearing the end of the interview, were asked to give suggestions which might alleviate any problems which they may experience or have experienced as a White educator in a predominantly Black college. The majority of participants discussed the idea of having a Black individual from the institution who could help them navigate the HBCU environment. Some faculty who expressed this need discussed the idea of someone to explain the history and culture of the campus. One male full professor explained:

I've been here [at the HBCU] for over a decade, and l've had to pick up a little bit of this and a little bit of that along the way. And it took time for me to string it all together. I was lost and confused many times. [Laughter] But I finally started to get a sense of what this campus was truly about after about five years... and I'm still not sure I understand everything. If it wasn't for some of my peers explaining the meaning behind some of the saying, events and sentiments on campus I would have no clue.... It was their explanations that helped me. If I had someone walk me through this from day one, I would have been fine earlier on in my career.

Having a cultural translator and someone from the HBCU to explain the environment would have helped this individual. A female assistant professor said:

I was hired with two other faculty [members] who were African American. They seemed to ease into the campus very well. The students seemed to relate to them better than they did to me.... We did lunch during the next semester and I shared my concerns and experiences. They started to 'school' me on Black colleges and how they [Black colleges] operate. That was my 'ah-ha' moment. I started to understand the difference between Black colleges and the colleges I was accustomed to.

Having a peer describe the nature of the HBCU campus became a very important element in the enlightening of the White faculty members. Having Black peers who have discussions about the history, nature, and operation of HBCUs may assist White faculty understand their surroundings. Nineteen of the 27 participants suggested that an individual such as a faculty peer or colleague would be a great way to assist with understanding the HBCU campus. Eleven of the participants suggested that administration such as department heads should assist White faculty members with their transition to a Black college. 


\section{Discussion}

In this study the participants spoke of being oblivious to the cultural nuances and significance of activities at Black colleges. Fostering understanding of the cultural environment is critically important, and at Black colleges it becomes imperative for their White faculty members. Therefore, creating an environment where the White members have an opportunity to understand the culture and become integrated participants into the community can be established by the development of mentoring dyads. Although referencing foreign teachers, Falicov (2009) believed that cultural attunement can develop through the ongoing study of coping mechanisms, viewpoints, values, stressors, and awareness of ethnic minorities within their culture. Thus the immersion of White faculty members at Black colleges is an opportunity for this ongoing development.

Isolation is one of the issues that plague many minority faculty members at institutions of higher education, a factor also reflected in the study. Participants reported that they experienced social isolation and professional marginalization based on their ethnicity at their HBCUs of employment. Murakami and Núñez (2014) posit that building a scholarly community can be fostered into a counternarrative to the isolation of underrepresented faculty. Thus Black colleges should seriously explore ways to engage their White faculty members in mentoring dyads with Black faculty members. These Black faculty members will be responsible for explaining the socio-cultural nuances and contexts of Black colleges and their communities. Combining this with participants' reporting that they become more culturally aware through time, HBCUs can reinforce understanding by pairing White faculty members with Black faculty members who can assist in the cultural translation of the environment.

As stated earlier, CRT is a movement by scholars and social activists whose aim is to create a greater understanding of the imbalances that exist as a result of race, racism, and power. The voices and perspectives expressed in this current study directly reflect the distresses some White faculty members experience from their subdominant status in their $\mathrm{HBCU}$ environment. While many participants discussed the development of personal awareness of culture and their contribution to the diversity on their campuses, they also shared their feelings of isolation and marginalization. At the same time, participants called for the Black faculty to serve as partners and mentors to the White faculty population to create a more understanding, accepting, and amiable campus climate. Willie (2000) states, "Some Whites can be mentors for Blacks and some men can be mentors for women. [However] research is needed on the outcomes of people of color serving as mentors for Whites..." (p. 258). However, White faculty members who participated in this study regarded their Black peers to be the possessors of social capital in the Black college environment and apt to be their mentors. 
Because of the collective experiences as a subdominant population in the greater society, Black faculty peers possess a greater societal experience that enables them to cope with minority status and truly understand the nuances and importance of cultural reinforcement for minority populations. Thus, Blacks have the knowledge and experiential base to be mentors to Whites with respect to coping with marginalization and unacceptance. This study coupled with Willie's charge (2000) spawns rich opportunities for HBCUs to deepen the cultural knowledge of their White faculty members. The CRT approach of this study gives the modern White faculty member at an HBCU a voice in the field that is seldom heard. If institutions consider and implement the recommended development of peer-mentoring, the experiences of this population will become more understood and validated. This greater understanding may assist in increasing the retention rates of the White faculty at HBCUs.

Louis' (2008) study yielded no group of White faculty reporting positive adjustment and satisfaction levels with their employment at a Black college. Louis states "that the HBCU environment was not the most amiable and/or favorable for White faculty" (p. 135). Addressing change within the environment must come from the constituents therein. Faculty members of influence, Black faculty members, should heed the charge of creating a more welcoming environment for their White colleagues. Faculty-peer mentoring may hold the key for initiating such change. Mentoring can be either formal or informal, but the basis of it must hinge on the transference of cultural knowledge and social capital that can assist White faculty members in adjusting to the HBCU environment.

When referencing cross-race mentoring, Stanley and Lincoln (2005) stressed, "The successful mentoring relationship, in our experience, is characterized by trust, honesty, a willingness to learn about self and others, and the ability to share power and privilege" (p. 46). Noting the narratives of participants gathered in this current study, these ideas can be crucial in the creation of a blueprint for the direction of any mentoring program. The development of faculty-peer mentoring at Black colleges may help White faculty members garner a greater understanding of the Black college environment. Topics that should be incorporated into these programs are (a) the history of Black colleges; (b) the struggles of Blacks in the greater society; (c) coping mechanisms that Black utilize to survive; (d) the importance of culture to the survival of the community; and (e) the contribution of Whites and other ethnicities in the struggles of Black America. Acquiring this knowledge can undoubtedly impact their perceptions of their station at the institution and may increase their adjustment to the environment. An honest exchange and acquisition of knowledge will undoubtedly promulgate greater levels of social capital. Montalvo (2013) states that type of capital can only be gained through individuals and their avenues of social relationships with other. This reinforces the need for Black and White faculty members to engage in meaning exchanges. A collaborative approach to addressing the adjustment of White faculty at Black colleges is necessary. 


\section{Recommendations}

The creation of intentional cross-cultural faculty peer mentoring pairings guided by a trained faculty development specialist can be of great benefit. The specialist can share feedback from both White and Black faculty participants, collect data, and offer suggestions for future action. The specialist can coordinate the entire effort and market the experience to new and old, White and Black faculty. In many ways a cross-cultural faculty peer mentoring program can be a paradigm changer for the Black college environment.

Although the impetus may be to have only new faculty involved in such a venture, it may be substantially more beneficial to invite seasoned faculty to participate in the mentoring process. However, it is necessary for the mentorprotégé essence of mentoring to have a more experienced faculty member paired with a less experienced. This also allows both Black and White senior faculty to mentor a faculty member of another ethnicity. The faculty pairs should be guided to explore and learn the environment together, and individuals can share insight on issues and events from their own cultural lens. Both parties should be willing to be open, hear contradicting perspectives, and discuss them. Having the specialist acting in the capacity of a mediator or facilitator at regular intervals to decode or translate their experiences to each individual will also allow for developing a cultural awareness of the other.

Louis and Michel (2013) believe that this ongoing cross-cultural interaction will foster self-reflection, reduce stereotyping, and promote an exchange of social capital between cultures:

Taking a mental assessment of one's own cultural features and biases, examining another's culture, making comparisons, citing differences, attempting to not judge, researching their cultural heritage, and then comprehending that the person with which one interacts is an individual and may not necessarily fall into a particular category within their own culture. (p. 216)

Thus the process becomes holistic and shared, and White faculty members are not left to interpret without translation of the HBCU environment.

To reinforce the cross-cultural faculty peer mentoring, workshops focusing on the cross-cultural nature of Black colleges should be offered to re-educate the individuals engaged in the mentoring process. These workshops should focus on the history of Black college as an institution and the contributions of Whites have had throughout its existence. For White faculty it will increase their understanding of their ethnic group's role in the institution. The workshop should also inform White faculty members of (a) the value of the HBCU in the preservation of the Black community; (b) the atrocities of the slavery, Jim Crow, and Civil Rights eras; and (c) racial discrimination as an ongoing major factor in the U.S. Black community and African American experience. For Black faculty the workshops 
should develop a greater appreciation of the collaboration that Whites had in the establishment and evolution of the Black college.

\section{Conclusion}

White faculty adjustment to minority status at Black colleges should be as much of a concern as Black, Latino, Asian, or Native American faculty adjustment at predominantly White universities (PWIs). However, the assessment of any group's experiences should be the first step in the process. Developing a guided cross-cultural mentoring program may be of great benefit to the individual and the institution. It also has to be a collaborative effort where various ethnicities are willing to engage in honest, difficult, and reflective exchanges. Adjustment cannot occur by itself; the support of cross-cultural mentoring by faculty peers, faculty development offices, department chairs, deans, and provosts is necessary. Each institution needs to integrate its unique history within this process so that it becomes meaningful for the participating faculty members.

Although this research has identified significant themes and suggested action for faculty development at Black colleges, it is indeed in the words of the participants that the crux of the matter is best expressed. A White male assistant professor suggested a solution that underscored the implementation of the results of the study:

We need multi-ethnic mediators and presenters to do some workshops to addresses the racial issues between Whites and Black faculty [members]. We need to increase communication and professionalism. We need diversity training across all levels of faculty. We need more efforts to transcend race and ethnicity and focus on humanity shared by all.

Simply put, positively adjusted faculty members can result in more engaged and motivated individuals who can provide better educational experiences for their students. Cross-cultural faculty mentoring can undoubtedly benefit both White and Black faculty at our nation's Black colleges.

\section{References}

Betsey, C. L. (2008). Historically Black colleges and universities. Piscataway, $\mathrm{NJ}$ : Transaction Publishers.

Bourke, B. (2014). Positionality: Reflecting on the research process. The Qualitative Report, 19(18), 1-9.

Butera, F., \& Levine, J. M. (2009). Coping with minority status: Responses to exclusion and inclusion. New York, NY: Cambridge University Press. 
Cooper, J. E., Massey, D. \& Graham, A. (2006). Being "Dixie" at a historically Black university: A White faculty member's exploration of Whiteness through the narratives of two Black faculty members. Negro Educational Review, 57(1), 127-140.

Creswell, J. W. (2008). Research design: Qualitative, quantitative, and mixed method approaches (3rd ed.). Thousand Oaks, CA: Sage.

Czujko, R., Ivie, R., \& Stith, J. H. (2008). Untapped talent: The African American presence in physics and the geosciences. (Report No. R-444). College Park, MD: American Institute of Physics Report.

Delgado, R., \& Stefancic, J. (1993). Critical race theory: An annotated bibliography. Virginia Law Review, 79, 461-516.

Delgado, R., \& Stefancic, J. (2006). Critical race theory: An introduction. Retrieved from http://www.nyupress.org/19309chapt1.php

Decuir, J., \& Dixson, A. (2004). So when it comes out, they aren't that surprised that it is there: Using critical race theory as a tool of analysis of race and racism in education. Educational Researcher, 33, 26-31.

Falicov, C. (2009). Commentary: On the wisdom and challenges of culturally attuned treatments for Latinos. Family Process, 48(2), 292-309.

Fanon, F. (1969). Black skin, White masks. New York, NY: Grove Press.

Foner, E. (2002). Reconstruction: America's unfinished revolution, 1863-1977. New York, NY: HarperCollins.

Foster, L. (2001). The not-so-invisible professors: White faculty at the Black college. Urban Education, 36(5), 611-629.

Foster, L., Guyden, J. A., \& Miller, A. L. (Eds.) (1999). Affirmed action: Essays on the academic and social lives of White faculty members at historically Black colleges and universities. Landham, MD: Rowman \& Littlefield.

Frey, W. H. (2012). Census projects new "majority minority" tipping points. Retrieved from http://www.brookings.edu/research/opinions/2012/12/13 census-race-projections-frey

Gasman, M. (2009). Diversity at the historically Black college and university. Retrieved from http://diverseeducation.wordpress.com/2009/06/06/ diversity-at-historically-black-colleges-and-universities/

Hiraldo, P. (2010). The role of critical race theory in higher education. The Vermont Connection, 31(1), 53-59.

Hubbard, D. (2006). The color of our classroom, the color of our future. Academe, 92(6), 27-29.

Kynard, C., \& Eddy, R. (2009). Toward a new critical framework: Colorconscious political morality and pedagogy at historically Black and historically White colleges and universities. National Council of Teachers of English, 61(1), 24-44. 
Ladson-Billings, G. (2005). The evolving role of critical race theory in educational scholarship. Race Ethnicity and Education, 8(1), 115-119.

Lincoln, Y. S., \& Guba, E. (1985). Naturalistic inquiry. Newbury Park, CA: Sage.

Louis, D. A., \& Michel, S. D. (2013). Frantz Fanon ambivalence revisited in America's faculty: Narratives of Black and White faculty struggles with cross cultural mentoring. National Journal of Urban Education \& Practice, 6(3), 214- 227.

Louis, D. (2008). Examining white faculty maladjustment at historically Black colleges and universities. National Journal of Urban Education \& Practice, 2(3), 146-158.

Maher, F. A., \& Tetreault, M.K. (1993). Frames of positionality: Constructing meaningful dialogues about gender and race. Anthropological Quarterly, 66(3), 118-126.

Montalvo, E. J. (2013). The recruitment and retention of Hispanic undergraduate students in public universities in the United States, 20002006. Journal of Hispanic Higher Education, 12(3), 237-255. doi:10.1177/1538192712470692

Murakami, E. T., \& Núñez, A. (2014). Latina faculty transcending barriers: Peer mentoring in a Hispanic-serving institution. Mentoring \& Tutoring: Partnership in Learning, 22(4), 284-301.

Patton, M. Q, (2001). Qualitative research \& evaluation methods. Thousand Oaks, CA: Sage.

Quaye, S. J., \& Harper, S. R. (2014). Student engagement in higher education: Theoretical perspectives and practical approaches for diverse populations. New York, NY: Routledge.

Reddick, R., \& Sáenz, V. (2012). Coming home: Hermanos académicos reflect on past and present realities as professors at their alma mater. Harvard Educational Review, 82(3), 353-380.

Roebuck, J. B., \& Murty, K. S. (1993). Historically Black colleges and universities: Their place in American higher education. Westrport, CT: Praeger.

Solórzano, D. G., \& Yosso, T. J. (2002). Critical race methodology: Counterstorytelling as an analytical framework for education research. Qualitative Inquiry. 8(1), 23-44.

Smith, W. A., Altbach, P. G., \& Lomotey, K. (2002). The racial crisis in American higher education: Continuing challenges for the twenty-first century. Albany, NY: SUNY Press.

Smith, S. L., \& Borgstedt, K. W. (1985). Factors influencing adjustment of white faculty in predominantly black colleges. Journal of Negro Education, 148 $-163$. 
Smith, J. A., \& Osborn, M. (2008). Interpretative phenomenological analysis. In J. Smith (Ed.), Qualitative Psychology (pp. 53-80). Thousand Oaks, CA: Sage.

Stanley, C. A., \& Lincoln, Y. S. (2005). Cross-race faculty mentoring. Change, $37(2), 44-50$.

Takacs, D. (2003). How does your positionality bias your epistemology? NEA Higher Education Journal, Summer, 27-38.

U. S. Department of Education (2014). White House Initiative on historically Black colleges and universities. Retrieved from http://www.ed.gov/ edblogs/whhbcul

Warnat, W. I. (1976). The role of White professors on the Black college campus. Journal of Negro Education, 334-338.

Willie, C. V. (2000). Confidence, trust and respect: The preeminent goals of educational reform. The Journal of Negro Education, 69(4), 255-262.

Willie, C. V., Reddick, R.J., \& Brown, R. (2006). The Black college mystique. Lanham, MD: Rowman \& Littlefield.

\section{Appendix A}

\section{Interview Questions for White Faculty members at predominantly Black Colleges}

1. Describe your overall experience as a faculty member at a historically Black college?

2. What do you see as especially positive about your experience as a White educator in a predominantly Black college?

3. What do you see as the most negative aspects of your experience as a White educator in a predominantly Black college?

4. Please describe ways in which you have addressed or coped with negative situations as a White educator at a predominantly Black college.

5. Describe your experience working with Black faculty members, administrators and students at a predominantly Black college.

6. What is the most difficult aspect of being a White educator at a predominantly Black college?

7. At a predominantly Black college racism and discrimination are pertinent issues that arise in conversations; describe your feelings when you are involved in discussions surrounding racism and discrimination. 
8. Describe experiences that have made you feel accepted as a member of the community at your predominantly Black college.

9. Describe experiences that have made you feel marginalized as a member of the HBCU community at your predominantly Black college.

10. What suggestions can you make, which might help alleviate any problems which you may experience or have experienced as a White educator in a predominantly Black college?

\section{Author Contact}

Dave A. Louis: dave.louis@ttu.edu

Texas Tech University, College of Education, Box 41071, Lubbock, TX 79409, U.S.A. 